\title{
ARTICLE
}

\section{Uncertainties in activity calculations of different nuclides in reactor steels by neutron irra- diation}

\author{
Joerg Konheiser* and Anna Ferrari \\ Helmholtz-Zentrum Dresden-Rossendorf e.V., P.O. Box 510119, 01314 Dresden, Germany
}

\begin{abstract}
Activation processes in a nuclear power plant are mainly due to neutron reactions. The determination of the neutron fluences in the reactor pressure vessel (RPV) is therefore the main task of the reactor dosimetry and the good experience for the activity evaluation has to be used. From 2005 to 2009 trepans were gained from the RPV of decommissioned nuclear power plant in Greifswald for the embrittlement investigation. For the first time, samples could be taken from the inner part of the RPV and activity measurements were performed. Experimental results were obtained for ${ }^{93} \mathrm{Nb},{ }^{63} \mathrm{Ni}$ and ${ }^{99} \mathrm{Tc}$. The calculations of the neutron fluences were carried out with the TRAMO Monte Carlo code. Based on these fluence values, the time-dependent activities of different nuclides were estimated. The calculated/experimental $(\mathrm{C} / \mathrm{E})$ activity ratios for the selected samples fluctuate between 0.37 and 0.91 for niobium, while for ${ }^{63} \mathrm{Ni}$ and ${ }^{99} \mathrm{Tc}$ they are approximately between 0.6 and 0.91 .
\end{abstract}

Keywords: Monte Carlo calculation; decommissioning; neutron fluence calculation; activity calculations

\section{Introduction}

Since more than 50 years nuclear power is used for energy generation. The first plants have reached their maximal possible operating time and are already shut down, while other plants have been shut down for political or safety reasons. Decommissioning is therefore necessary for these plants. In the decommissioning process the radioactivity of the reactor components is of crucial importance. One of most radiolabeled component is the reactor pressure vessel (RPV).

Since the pressure vessel activation is mainly due to neutron capture processes, it depends on the mixture of steel and on neutron fluences in the thermal energy region. The radiation embrittlement of RPV steel in mixed neutron-gamma fields is mostly determined by fast neutrons, but also by thermal neutron or gamma radiation. The determination of these fluences is the main task of the reactor dosimetry and therefore the good experience for the activity evaluation should be used.

From 2005 to 2009 trepans were gained from the RPV of decommissioned nuclear power plant (NPP) in Greifswald for the embrittlement investigation. For this it was necessary to determine the in-depth neutron fluences in the samples. The calculations were carried out with TRAMO, a multigroup Monte-Carlo code for neutron and gamma ray transport calculations. It is an in-house development. Moreover, the time-dependent activities of the main nuclides of RPV were also esti- mated for the decommissioning.

The calculated fluences were validated by measurements. At first, with the aim to validate the results, samples were cut out from the trepan and the measured ${ }^{93 \mathrm{~m}} \mathrm{Nb}$ activity was compared with the calculated quantity. ${ }^{93 \mathrm{~m}} \mathrm{Nb}$ is in our case the only possible standard monitor, due to the half-life of 16.13 years.

Niobium is only a trace element in the RPV-Steel, Therefore, a try was carried out to validate the calculations through the analysis of other activated nuclides, provided that the parent elements are available and determinable and that the activities of the daughter nuclides are measurable. Possible nuclides are ${ }^{63} \mathrm{Ni},{ }^{14} \mathrm{C}$, ${ }^{99} \mathrm{Tc},{ }^{60} \mathrm{Co},{ }^{121} \mathrm{Sn}$ and, because of the high concentration, ${ }^{55} \mathrm{Fe}$. In this paper the possible reactions of single nuclides are analyzed, the generated activities are determined and the probable sources of error are discussed.

The analysis has been focused in particular on nickel and technetium. They are especially important in the decommissioning of the plants because they produce the main part of the activity after the ${ }^{60} \mathrm{Co}$ decay. The ${ }^{63} \mathrm{Ni}$ activity is practically produced by the neutron capture reaction of ${ }^{62} \mathrm{Ni}$ and by the $(\mathrm{n}, \mathrm{p})$ reaction of ${ }^{63} \mathrm{Cu} .{ }^{63} \mathrm{Ni}$ is, consequently, a main thermal neutron monitor with a half-life of 100 years. ${ }^{99} \mathrm{Tc}$ is produced from ${ }^{98} \mathrm{Mo}$ by the neutron capture reaction and can be considered, with a half-life of 210000 years, as stable.

*Corresponding author. Email: j.konheiser@hzdr.de 


\section{Monte Carlo program TRAMO}

TRAMO [1] is a multigroup Monte Carlo code for neutron and gamma ray transport calculations. The code was developed especially for reactor dosimetry purposes and shielding problems. It was tested and validated in relevant benchmarks. The geometrical options are optimized for fission reactor geometry. The basic geometry is a system of not intersecting bodies arbitrarily nested among each other and all having parallel axes. Theses bodies can have independent and arbitrary subdivisions in vertical direction. To speed up the calculations, special routines for typical reactor geometries were implemented (for example hexagons). The most essential support to obtain results with low statistical error is a reasonable set of forced weights. For the calculation of these optimal weights the code TRAWEI was developed (Monte-Carlo Code with the help of recursive procedures) [1].

The program has an own data supply. On the basis of microscopic group cross sections generated by NJOY [2] the code MODAJ [1] provides macroscopic cross sections using factors for different dilutions and temperatures. Equiprobable angular intervals for different energy points are used for the treatment of elastic scattering and scattering in the thermal region. The $\mathrm{P}_{\mathrm{L}}$-approximation is applied for all non-elastic scatterings and gamma scattering. The numbers of groups is variable.

\section{NPP Greifswald}

In the north east of Germany, at the GDR time, 4 units of the Russian NPP type WWER-440/230 were in operation between 1973 and 1990 .

The unit 1 and 2 are between the first units of type WWER440/320. They are somehow different from the units 3 and 4. A significant difference is the absence of cladding on the inner surface of the RPV. Generally the WWER reactors are built in a very compact way. Therefore, the RPV have high neutron fluences. To reduce the fluences, dummy cassettes were inserted in the outer core row, for example in unit 1 . In addition, in the units 1 to 3 the critical weld was annealed.

The operation was stopped after the German reunification, because the units did not completely follow western nuclear safety standards. Material probes from the pressure vessels were gained in the frame of the ongoing decommissioning procedure. The investigation of this material is described in [3].

\section{Calculations}

\subsection{Input data and Calculation option}

Full geometrical information was used for the investigated unit. The $30^{\circ}$ symmetry is typical for VVER cores. Because neighboring $30^{\circ}$-sectors shown slightly asymmetrical source distributions, a $60^{\circ}$ sector had to be used for the calculation model.
For the calculations the assembly structure was homogenized. In contrast, the sources were pin-wise started. Here, the homogenization would lead to a considerable error. The fission products were neglected. The necessary source data were calculated based on the power data of all cycles of the NPP. The source distribution was given pin-wise in the outer fuel assembly rows. The neutron source data were available for all cycles, assemblies, 10 height layers and for time steps of about 20 effective days. By default neutrons were originated in the outer three rows of fuel assemblies. As shown by a first set of calculations, the fraction of the inner sources gives a negligible contribution to the neutron fluence on the RPV and can be therefore neglected.

Figure 1 shows the horizontal sectional drawing of the model used in the calculation at the height of the reactor core with dummy assemblies. Dummy assemblies (with structure) were inserted in the outer assembly rows in the last 4 cycles of unit 1. A separate model was used for these cycles. The red assemblies have sources and the yellow assemblies serve as reflector.

The ENDF/B-VI (B6) and newest ENDF/B-VII (B7) nuclear data libraries were used for the group section calculations. The SAND II structure with 640 groups for neutrons and the CSEWG structure with 94 groups for gammas were the standard group structure. Scattering matrices, calculated with the help of the free gas model

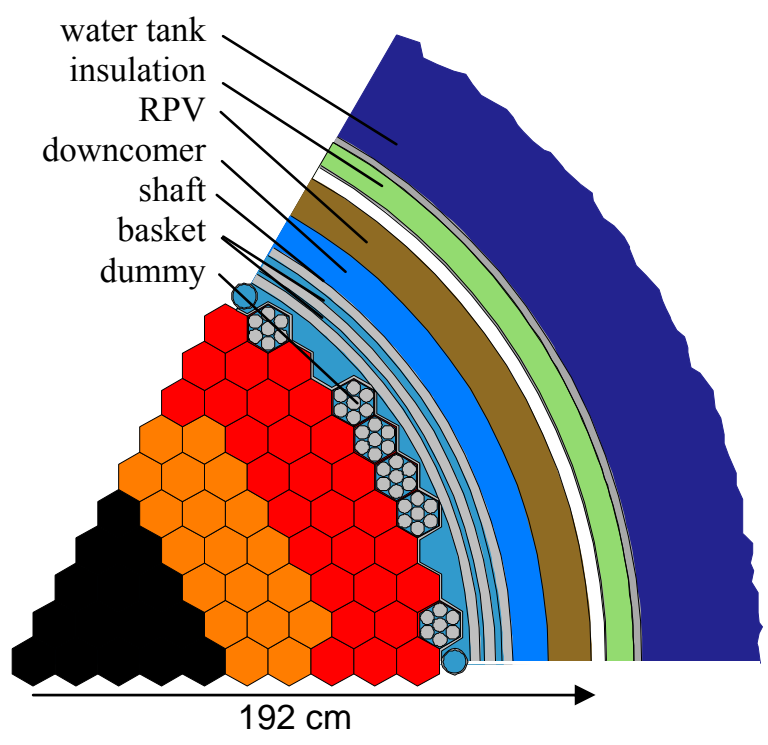

Figure 1. Horizontal drawing in the core region of the calculation model of TRAMO with dummy, sources (red), refection (yellow) and black assemblies.

or with the momentum and energy transfer factors $\alpha, \beta$ [4], were used for the thermal scattering.

Different techniques were used for the variance improvement. Besides a source biasing, the "Weight window" method is primarily used. Moreover, the upper energy groups were separately calculated, with the effect of a strong reduction of the statistical errors in these groups.

The surface fluences were determined in steps of 1 
$\mathrm{cm}$ for each trepan. The thickness of the RPV is $14 \mathrm{~cm}$ and hence 15 values were calculated. A distribution on these surfaces can be calculated by their fragmentation. The activities were determined based on the calculated flunece spectra, the reaction cross sections and the half-life and were compared with the experiment.

\subsection{Comparison of fluences}

The influence of the data library, of the number of energy groups and of the thermal scattering matrix on the neutron fluence was studied. Calculations with B6 and B7 data were carried out. The energy was from 20 $\mathrm{MeV}$ to $0.0001 \mathrm{eV}$ in two energy groups (47 and 640) and the two scattering models (see 4.1) were used. The reference values $C_{R}$ were calculated with $B 7$ data, 640 energy groups and using Alfa/beta factors for the thermal matrix.

The comparison between the different thermal scattering matrices showed that their influence can be neglected. Table 1 shows therefore only the comparison $\left(\mathrm{C} / \mathrm{C}_{\mathrm{R}}\right)$ between the results obtained using different group numbers and libraries, for fluences evaluated on the inner surface (inside), $7 \mathrm{~cm}$ from the inner surface (middle) and on the outer surface (outside) of the RPV.

Table $1 . \mathrm{C} / \mathrm{C}_{\mathrm{R}}$ ratio between the results of different calculations in different points of RP.

\begin{tabular}{|c|c|c|c|c|}
\hline Comparison & energy & inside & middle & outside \\
\hline \multirow{2}{*}{$\begin{array}{c}\text { B7 47 / } \\
\text { B7 640 }\end{array}$} & fast & 1.03 & 0.98 & 0.95 \\
\cline { 2 - 5 } & thermal & 0.91 & 0.80 & 0.61 \\
\cline { 2 - 5 } & total & 0.97 & 1.00 & 0.96 \\
\hline \multirow{2}{*}{$\begin{array}{c}\text { B6 47 / } \\
\text { B7 47 }\end{array}$} & fast & 0.81 & 0.84 & 0.83 \\
\cline { 2 - 5 } & thermal & 0.83 & 0.70 & 0.59 \\
\cline { 2 - 5 } & total & 0.83 & 0.84 & 0.86 \\
\hline
\end{tabular}

Larger differences were found in the results between the 47 and 640 group calculations especially in the thermal energy region. The values computed with 640 groups are considerably higher. This effect is caused by the conversion of resonances when at the group cross sections are produced and is also dependent on the local conditions. In most cases it results in an overestimation of the cross sections. The effect can be minimized by the use of fine energy groups. A correct calculation of the thermal fluence is important for the determination of the activities.

The relatively big difference between the B6 and B7 calculations was surprising. Bigger values - on average $15 \%$ - were calculated with the new data. Calculations based on the JENDL3.3 nuclear data library were also carried out. The results were practically identical to the reference values. This shows that the differences are reduced in the libraries.

\section{Selected isotopes of PPV for evaluation}

Isotopes with long half-lives are important in the de- commissioning of NPPs. Even with very little concentrations, few of them can determine the radiation level in the steel at long cooling times. Since the standard monitors of the classic reactor dosimetry have relatively short half-lifes, the experience can be used only conditionally. For our purpose, only niobium and cobalt can be used.

With the exception of ${ }^{60} \mathrm{Co}$, the important nuclides of activity development $-{ }^{63} \mathrm{Ni},{ }^{99} \mathrm{Tc}$ and ${ }^{14} \mathrm{C}$ - are not standard monitors. They produce the main part of the activities after the ${ }^{60} \mathrm{Co}$ decay. However, these nuclides are determined by default in clearance measurements of activated steel. The corresponding methods for the activity estimation exist and therefore can be used. Table 2 shows production reactions, half-lifes and average concentration of these nuclides in the RPV steel.

Table 2. Production reactions, half-life time and average concentration of the main radionuclides in the RPV steel.

\begin{tabular}{|c|c|r|r|}
\hline & reaction & half-life & $\begin{array}{r}\text { part in the } \\
\text { RPV-steel }\end{array}$ \\
\hline $\mathrm{Ni}$ & ${ }^{62} \mathrm{Ni}(\mathrm{n}, \mathrm{g})^{63} \mathrm{Ni}$ & $100 \mathrm{y}$ & $2000 \mathrm{ppm}$ \\
\hline $\mathrm{Mo}$ & ${ }^{98} \mathrm{Mo}(\mathrm{n}, \gamma)^{99} \mathrm{Mo} \rightarrow{ }^{99} \mathrm{Tc}$ & $210000 \mathrm{y}$ & $4000 \mathrm{ppm}$ \\
\hline $\mathrm{N}$ & ${ }^{14} \mathrm{~N}(\mathrm{n}, \mathrm{p})^{14} \mathrm{C}$ & $5700 \mathrm{y}$ & $60 \mathrm{ppm}$ \\
\hline $\mathrm{Ni}$ & ${ }^{58} \mathrm{Ni}(\mathrm{n}, \gamma)^{59} \mathrm{Ni}$ & $75000 \mathrm{y}$ & $2000 \mathrm{ppm}$ \\
\hline $\mathrm{Co}$ & ${ }^{59} \mathrm{Co}(\mathrm{n}, \gamma)^{60} \mathrm{Co}$ & $5.3 \mathrm{y}$ & $30 \mathrm{ppm}$ \\
\hline $\mathrm{Nb}$ & ${ }^{93} \mathrm{Nb}\left(\mathrm{n}, \mathrm{n}^{\prime}\right)^{93 \mathrm{~m}} \mathrm{Nb}$ & $16.3 \mathrm{y}$ & $2 \mathrm{ppm}$ \\
\hline
\end{tabular}

With the exception of ${ }^{93 \mathrm{~m}} \mathrm{Nb}$, all reactions are thermal capture reactions. The threshold energy of the inelastic scattering is approximately $0.1 \mathrm{MeV}$. Unfortunately, ${ }^{93 \mathrm{~m}} \mathrm{Nb}$ results also by the thermal capture reaction of ${ }^{92} \mathrm{Mo}$. Mo is a usual constituent of RPV steels.

\section{C/E comparison}

\subsection{Experiment}

The "Verein für Kernverfahrenstechnik und Analytik" in Dresden has carried out the experimental determination of the activities. The activities of nuclides ${ }^{93 \mathrm{~m}} \mathrm{Nb},{ }^{99} \mathrm{Tc}$, and ${ }^{63} \mathrm{Ni}$ were determined. The radionuclide ${ }^{14} \mathrm{C}$ could not be considered because the nitrogen concentrations could not be measured $\left({ }^{14} \mathrm{C}\right.$ is produced by $(n, p)$ reaction from $\left.{ }^{14} \mathrm{~N}\right)$.

The preferred measuring method of the activities was liquid scintillation counting (LSC) and of the quantity was inductively coupled plasma mass spectrometry (ICP-MS). The radiochemical separation is based on anion exchange chromatography. The statistical uncertainty of the LSC measurements was very low $(<3 \%)$ and the one of the ICP-MS is approximatly at the level of $5 \%$.

The radiochemical separation of niobium is described in detail in [5]. Standard techniques from the decommissioning were used for the chemical processing of nickel 
and technetium. The measured activities of nickel are due to superposition of ${ }^{59} \mathrm{Ni}$ and ${ }^{63} \mathrm{Ni}$ activities. Separation of the results is not possible with LSC measurement, but activity is $99 \%{ }^{63} \mathrm{Ni}$ due to long half life time of ${ }^{59} \mathrm{Ni}$.

\subsection{Comparison}

Samples were taken at different depth of the RPV and the activities from ${ }^{93 \mathrm{~m}} \mathrm{Nb},{ }^{63} \mathrm{Ni}$ and ${ }^{99} \mathrm{Tc}$ in them were determined. Tables $\mathbf{3}$ and $\mathbf{4}$ show the comparisons. ${ }^{93 \mathrm{~m}} \mathrm{Nb}$ was measured in seven samples, while ${ }^{63} \mathrm{Ni}$ and ${ }^{99} \mathrm{Tc}$ in two samples. The weights of these samples were 0.5 to $1 \mathrm{~g}$.

Table 3. Measured and calculated activities of ${ }^{93 \mathrm{~m}} \mathrm{Nb}$ and their $\mathrm{C} / \mathrm{E}$ ratios in the RPV of unit 1.

\begin{tabular}{|c|c|c|c|}
\hline \multirow{2}{*}{ Distance* } & \multicolumn{2}{|c|}{ activities Bq/g } & \multirow{2}{*}{$\mathrm{C} / \mathrm{E}$} \\
\cline { 2 - 3 } & Experiment & Calculation & \\
\hline 0.0 & 479 & 261 & 0.54 \\
\hline 1.0 & 998 & 196 & 0.20 \\
\hline 2.0 & 288 & 139 & 0.48 \\
\hline 4.5 & 104 & 105 & 1.01 \\
\hline 7.0 & 79 & 80 & 1.01 \\
\hline 9.0 & 121 & 71 & 0.59 \\
\hline 11.0 & 38 & 43 & 1.13 \\
\hline
\end{tabular}

* Distance from inner RPV side in $\mathrm{cm}$

Table 4. Measured and calculated activities of ${ }^{63} \mathrm{Ni}$ and of ${ }^{99} \mathrm{Tc}$ and their $\mathrm{C} / \mathrm{E}$ ratios in the RPV of unit 1.

\begin{tabular}{|c|c|c|c|}
\hline \multirow{2}{*}{ Distance* } & \multicolumn{2}{|c|}{ activities Bq/g } & \multirow{2}{*}{$\mathrm{C} / \mathrm{E}$} \\
\cline { 2 - 3 } & Experiment & Calculation & \\
\hline \multicolumn{4}{|c|}{${ }^{63} \mathrm{Ni}$} \\
\hline 4.5 & 11200 & 9074 & 0.81 \\
\hline 7.0 & 5200 & 4022 & 0.77 \\
\hline \multicolumn{3}{|c|}{${ }^{99} \mathrm{Tc}$} \\
\hline 4.5 & 28.9 & 26.3 & 0.91 \\
\hline 7.0 & 21.2 & 19.3 & 0.91 \\
\hline
\end{tabular}

*Distance from inner RPV side in $\mathrm{cm}$

In Table 3 the calculated ${ }^{93 \mathrm{~m}} \mathrm{Nb}$ activities generated on both paths are shown. Because of variations of the niobium (1 to $2.5 \mathrm{ppm}$ ) and molybdenum (5500 to 6500 ppm) content in the samples, a clear dependence along the trepan axis cannot be expected. On the other hand, uncertainties must be assumed at the sample taking. Therefore, the information on the distances in the experiments should be considered as approximate values. Concerning the published values in [6], better convergence could be obtained to the experiments by the reduction of the statistical errors. However, the systematic discrepancies are always present. The possible causes of the discrepancies were already discussed in [6]. One reason could be the very small concentration of niobium and then error associated in the measurement.

Table 4 shows the $\mathrm{C} / \mathrm{E}$ ratios of the ${ }^{63} \mathrm{Ni}$ and ${ }^{99} \mathrm{Tc}$. The good results of the 47 group calculations of [6] could not be improved. For all samples, the calculated activities are smaller than the measured. On the one hand, small errors - for example in the material densities
- could have a influence on thermal fluences and consequently on the calculated values. Moreover, the measurements can also be influenced by impurities.

\section{Conclusion}

In this work the influence of different factors on the neutron fluence results were examined. It was shown that a change of energy groups can produce an increase of $40 \%$ of the thermal fluence in the presented example. In contrast, the changes are small in the fast energy region.

It was shown that, for the single activity, the calculation results can be validated by analyzing the nuclides contained in the RPV material. Despite the many different influences on the results, good agreement was achieved between the calculated and measured activities selectively. The results from [6] could be improved. In case of ${ }^{93 \mathrm{~m}} \mathrm{Nb}$ was shown that acceptable agreement can be achieved also at very small concentrations. On the other hand, the results show that the reason for the differences is probably in the experiments. Comparative measurements are needed here. In the case of ${ }^{63} \mathrm{Ni}$ and ${ }^{99} \mathrm{Tc}$, the systematic differences indicate potentially an insufficient calculation of the thermal energy range.

The reactor dosimetry has a long experience in the field of the calculation of neutron fluences in the fast energy range in the RPV. This is reflected in the results for ${ }^{93 \mathrm{~m}} \mathrm{Nb}$. In contrast, the thermal energy range is investigated only in recent years in the reactor dosimetry. It can be assumed that the results will be adjusted by the improvement of transport programs. Irrespective of this, the influence of uncertainty will be always bigger.

\section{References}

[1] H.-U. Barz, B. Böhmer, J. Konheiser and I. Stephan, High-Precision Monte Carlo Calculations, Experimental Verification and Adjustment of Fluences in the Pressure Vessel Cavity of a VVER-1000, Proc. ANS Radiation Protection and Shielding Division Topical Conference Technologies for the New Century, April 19-23, 1998, Nashville, Tennessee, USA, (1998) Vol. 1, p. 447-454, ISBN 0-89448-637-3.

[2] R. E. MacFarlane and D. W. Muir, The NJOY Nuclear Data Processing System (Version 91), Los Alamos, (1994) LA-12740-M.

[3] J. Schuhknecht, U. Rindelhardt and H.-W. Viehrig, Study of beltline weld and base metal of WWER-440 first generation reactor pressure vessel, Strength of materials 403 (2010)1, pp. 95-104.

[4] D.E. Parks, M S. Nilkin, J. R. Beyster and N.F. Wikner, Slow Neutron Scattering and Thermalization, W.A. Benjamin, Inc. New York, (1970).

[5] L. B. Baers and E. K. Hasanen, Experimental Estimation of Neutron Fluxes from Niobium Impurities in the Pressure Vessel Steel of Nuclear Power 
Reactors, Nucl. Instrum. Methods Phys. Res., Vol. A317, (1992) pp. 577-580.
[6] J. Konheiser, S. Mittag and H.-W. Viehrig, Application of Different Nuclides in Retrospective Dosimetry, Journal of ASTM International, Volume 9, Issue 3(2012). 